\title{
Antioxidants Reverse Age-Related Collateral Growth Impairment
}

\author{
Steven J. Miller ${ }^{a}$ b Brian J. Coppinger ${ }^{b} \quad$ Xiaosun Zhou $^{a} \quad J^{\prime}$ Beph L. Unthank ${ }^{a, b}$ \\ Departments of a Surgery and ${ }^{b}$ Cellular and Integrative Physiology, Indiana University School of Medicine, \\ Indianapolis, Ind., USA
}

\section{Key Words}

Apocynin $\cdot$ Arteriogenesis $\cdot$ Nitric oxide $\cdot$ Tempol

\begin{abstract}
Aging is a major risk factor for the development of cardiovascular diseases, including arterial occlusive disease. Oxidant stress increases with age, and may be a significant factor contributing to vascular dysfunction and disease. We have shown that aging and hypertension impair collateral growth, the natural compensatory response to arterial occlusive disease, and that antioxidants restore collateral growth in young hypertensive rats. The aim of this study was to test the hypothesis that oxidant stress mediates collateral growth impairment in nondiseased, aged rats. Ileal arteries were induced to become collaterals via ligation of adjacent arteries. Growth was assessed at 7 days by repeated in vivo measurements and comparison to same-animal control arteries. Collateral diameter enlargement did not occur in aged rats, but luminal expansion was stimulated by pretreatment with tempol. Co-administration of L-NAME with tempol prevented tempol-mediated collateral development. Expression of p22 ${ }^{\text {phox }}$ mRNA was increased in aged versus young rat arteries, suggesting $\mathrm{NAD}(\mathrm{P}) \mathrm{H}$ oxidase as a source of reactive oxygen species. Treatment with apocynin increased collateral growth capacity, whether administered prior to, or 7 days following, arterial ligation. The results suggest that antioxidant treatment may be useful in promoting collateral growth to compensate for age-related arterial occlusive disease.
\end{abstract}

Copyright $\odot 2009$ S. Karger AG, Basel

\section{Introduction}

The prevalence of cardiovascular disease, including arterial occlusive disease, increases with age $[1,2]$. A normal compensatory response to arterial occlusion is the flow-mediated enlargement of preexisting vessels, or collaterals, that bypass the site of occlusion and supply blood to distal ischemic tissues [3]. This process, referred to as collateral growth or arteriogenesis, is inhibited in both humans and animals during aging [4-6]. Although functional and structural changes are known to occur in the vasculature with age, the mechanisms responsible for impaired collateral growth are unclear. Increased oxidant stress, due to elevated reactive oxygen species (ROS) production or to decreased function of natural antioxidant pathways, has been shown to increase with age $[5,7,8]$ and may be a factor in inhibiting compensatory remodeling. Nitric oxide (NO) is required for both normal vascular function and collateral growth $[9,10]$, and its bioavailability may be negatively impacted by oxidative stress via scavenging by superoxide [11] or by other related mechanisms, such as endothelial NO synthase (eNOS) uncoupling [12]. Preclinical $[8,13]$ and human $[14,15]$ studies have demonstrated that antioxidants may be used to reverse age-associated endothelial dysfunction, consistent with a role for redox regulation of NO-dependent vascular function during aging.

Potential effects of age-related oxidant stress on collateral growth have not been extensively studied. Previous work in our laboratory [6] has demonstrated collat-

\section{KARGER}

\section{(C) 2009 S. Karger AG, Base}

Fax +41613061234 E-Mail karger@karger.ch www.karger.com www.karger.com/jvr
Prof. Steven J. Miller

Department of Surgery, Indiana University School of Medicine

1001 West Tenth Street, WD OPW 425F

Indianapolis, IN 46202-2879 (USA)

Tel. +1 317274 2657, Fax +1 317274 7334, E-Mail sjmiller@iupui.edu 
eral growth impairment in a rat model of aging. We have also demonstrated that the impairment in collateral growth in young spontaneously hypertensive rats (SHR) could be completely reversed by antioxidant treatment, including tempol and apocynin [16]. SHR have metabolic features similar to aging in that oxidative stress is increased $[8,17]$. The objective of this study was to test the hypothesis that oxidant stress mediates the age-related collateral growth impairment and that anti-oxidant treatment administered subsequent to an arterial occlusion can reverse the impairment. This approach was pursued because vascular disease typically is in progress before treatment begins. Age-related and antioxidant effects on collateral growth were assessed with our established mesenteric model [18]. Tempol and apocynin were used as antioxidants that act through different mechanisms. Our results demonstrate that oxidative stress is present in aged resistance arteries and that pretreatment with either tempol or apocynin partially reverses the age-related impairment in collateral growth. These data establish that excessive levels of ROS are in part responsible for the inhibition of compensatory vascular remodeling. We also demonstrate that the administration of apocynin subsequent to arterial ligation reverses the collateral growth impairment in aged rats. Thus, a form of antioxidant therapy may be useful for treating age-related arterial insufficiency in the presence of ongoing occlusive disease.

\section{Methods}

\section{Animals and Groups}

All procedures performed in this study were approved by the Indiana University School of Medicine Institutional Animal Care and Use Committee. Young ( $\sim 200 \mathrm{~g}, 2-3$ months) and old (retired breeder) male Wistar (>600 g, 8-12 months) and Wistar-Kyoto (WKY, 355-390 g, 8-12 months) rats were obtained from Harlan (Indianapolis, Ind., USA) and acclimated for a minimum of 3 days prior to use. Since retired breeder Wistar and WKY rats are approaching $50 \%$ of their mean survival age, we consider them to be a suitable model of early aging. Apocynin (acetovanillone) was obtained from Fisher Scientific (Hampton, N.H., USA); 4-hydroxy-2,2,6,6-tetramethylpiperidine-N-oxide (tempol) and $\mathrm{N}^{\mathrm{G}}$ nitro-L-arginine methyl ester (L-NAME) were purchased from Sigma (St. Louis, Mo., USA). For pretreatment, all drugs were administered in drinking water 3 days prior to model creation and maintained until vessel diameters were obtained. For posttreatment, apocynin was administered in drinking water starting 7 days following model creation and maintained for an additional 7 days when vessel diameters were measured. Concentrations/ doses were based upon studies that have demonstrated effectiveness in reducing oxidative stress [19-21], normalizing arterial ROS and NO concentrations [22], or affecting arterial remodeling [16]. Concentrations in drinking water were $5.0 \mathrm{~mm}$ for tempol
$(58.8 \pm 3.22 \mathrm{mg} / \mathrm{kg} /$ day $)$ and $3.0 \mathrm{~mm}$ for apocynin $(32.5 \pm 1.36$ $\mathrm{mg} / \mathrm{kg} /$ day). In an additional set of tempol-treated rats $(\mathrm{n}=4)$, a low dose of the eNOS inhibitor L-NAME $(0.1 \mathrm{mM} ; 1.6 \pm 0.07 \mathrm{mg}$ / $\mathrm{kg} /$ day) was added along with tempol in drinking water.

\section{Model of Collateral Growth and Its Assessment}

Experiments utilized a well-established model of mesenteric artery collateral growth as previously described [18]. This model uses sequential ligation of mesenteric arteries to create a flow-dependent collateral pathway. It has the advantage of easy and rapid access, a well-defined two-dimensional pathway, and allows repeated assessments of arterial diameters over time. It also enables comparison of collateral arteries to in-animal control arteries that have experienced similar manipulations, but not increased flow. Briefly, a laparotomy was performed and the terminal ileum exteriorized into a heated tissue support chamber. The bowel and mesentery were immersed in phosphate-buffered saline (PBS) or covered with plastic wrap at all times. Several sequential ileal arteries were ligated such that a region of bowel containing $\sim 45$ microvascular perfusion units was dependent upon collateral arteries for perfusion. Digital images of collateral and same-animal control arteries were acquired under conditions of maximal dilation (1.0 $\mathrm{mM}$ adenosine and $0.1 \mathrm{mM}$ sodium nitroprusside) with a dissecting microscope (Leica MZ 9.5) and camera (Spot Insight 4 Firewire). The bowel was returned to the abdominal cavity and the incision closed in two layers with 4-0 suture. After 7 (pretreatment) or 14 (posttreatment) days, the laparotomy and acquisition of digital images was repeated, inner arterial diameter was determined by measuring the red cell column with image analysis software (Image-J), and the percent change in diameter was calculated.

\section{Quantitative RT-PCR}

Relative differences in mesenteric artery mRNA expression were determined using real-time quantitative PCR. For vessel isolation to obtain RNA, the abdominal aorta of an anesthetized rat was cannulated above the iliac bifurcation. After ligating both renal arteries and the proximal aorta, the mesenteric circulation was perfused with $30 \mathrm{ml}$ of cold PBS followed by $10 \mathrm{ml}$ of RNAlater $^{\mathrm{TM}}$ (Ambion, Austin, Tex., USA). Mesenteric arteries were isolated, excised, and preserved in RNAlater at $-20^{\circ} \mathrm{C}$ prior to RNA isolation. Tissues were weighed, disrupted using a bead homogenizer (FastPrep System ${ }^{\circledR}$; QBIOgene, Carlsbad, Calif., USA), and total RNA was purified using an RNeasy ${ }^{\circledR}$ Fibrous Tissue Mini Kit (Qiagen, Valencia, Calif., USA). RNA sample concentration was determined using A260/A280 (NanoDrop ND1000 Spectrophotometer; NanoDrop Technologies, Wilmington, Del., USA) and RNA integrity was assessed by analysis with an Agilent 2100 Bioanalyzer (RNA 6000 Nano Chip Kit; Agilent, Santa Clara, Calif., USA). Aliquots of purified total RNA (0.5 $\mu \mathrm{g})$ were enzymatically treated to remove contaminating genomic DNA (DNAfree ${ }^{\mathrm{TM}}$; Ambion) and then reverse transcribed using ReadyTo-Go You-Prime First-Strand Beads (GE Healthcare/Amersham Biosciences, Piscataway, N.J., USA) with random decamer priming. For PCR, aliquots of cDNA (5.0 $\mu 1,1: 50$ dilution) were combined with primers and probes for either $\mathrm{p} 22^{\text {phox }}$ or $\beta$-actin endogenous control (TaqMan ${ }^{\circledR}$ Gene Expression Assays; Applied Biosystems, Foster City, Calif., USA) in the presence of a PCR mastermix (QuantiTect ${ }^{\mathrm{TM}}$ Probe PCR Kit; Qiagen). Reactions were run in triplicate on an Applied Biosystems 7500 Real-Time 
PCR System using relative quantification (ddCt) with dual-labeled (FAM/MGB) probes as the product detection method. Standard 7500 PCR cycling conditions were used. Differences in PCR product yields between groups were determined by comparing the fold differences between target mRNA after normalization to $\beta$-actin.

\section{Statistics}

Statistical analyses were done by one- or two-way repeatedmeasures ANOVA (SigmaStat 3.0). When significance between groups was detected, multiple pairwise comparisons were performed with the Holm-Sidak method. Data are presented as group averages with SE of the mean. The criterion for significance was $\mathrm{p}<0.05$.

\section{Results}

Tempol Reverses the Impairment in Collateral Growth

We have previously shown [6] that collateral growth was impaired in retired breeder Wistar rats compared to young rats ( $\sim 2-3$ months). To test the possible involvement of oxidant stress in the suppression of collateral growth, Wistar retired breeder rats were pretreated with the superoxide dismutase mimetic tempol for 3 days prior to, and for 7 days following, model creation. Collateral growth was assessed 7 days after ligation as described in the Methods. Similar to previous results, collateral artery diameters significantly increased $(33.0 \pm 4.3 \%, \mathrm{p}<$ 0.05 ) in young rats (data not shown), whereas no significant increase in collateral diameter was detected in untreated retired breeders (fig. 1). Collateral artery diameters in tempol-treated aged rats increased $17.6 \pm 5.8 \%$ ( $\mathrm{p}=0.03$ ) compared to same-animal controls. Inclusion of a low (non-hypertensive) dose [23] of the NOS inhibitor (L-NAME; $0.025 \mathrm{mg} / \mathrm{ml}$ ) completely inhibited tempol-assisted collateral growth, showing that the process is dependent on NO generation (fig. 1).

\section{NAD $(P) H$ Oxidase as a Source of Oxidant Stress}

Vascular oxidant stress has been shown to increase with aging $[5,7,8]$ and $\mathrm{NAD}(\mathrm{P}) \mathrm{H}$ oxidase is thought to be a major source of vascular superoxide [7, 8, 24, 25]. We examined mRNA expression of an $\mathrm{NAD}(\mathrm{P}) \mathrm{H}$ oxidase subunit in mesenteric arteries of young and retired breeder rats. Levels of $\mathrm{p} 22^{\text {phox }} \mathrm{mRNA}$ were found to be increased $1.5 \pm 0.2$ times in control arteries of aged compared to young rats (fig. 2), suggesting an increase in $\mathrm{NAD}(\mathrm{P}) \mathrm{H}$ oxidase activation, and thus production of superoxide.

Since increases in superoxide due to $\mathrm{NAD}(\mathrm{P}) \mathrm{H}$ oxidase activation could limit the bioavailability of $\mathrm{NO}$ [11] and inhibit collateral growth in aged animals, we tested

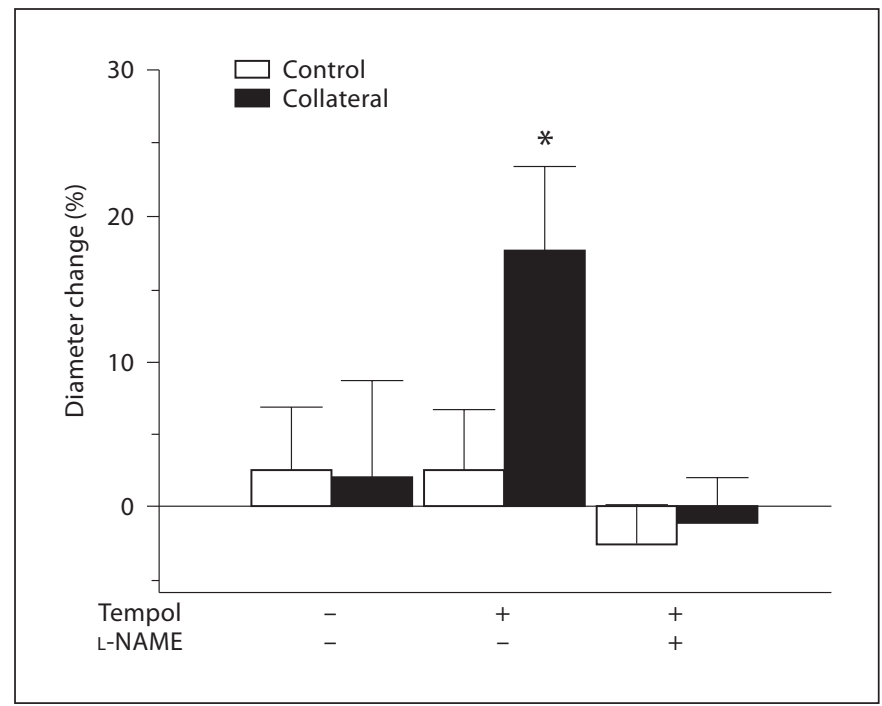

Fig. 1. Tempol reverses age-related collateral growth impairment. Diameter change of control and collateral vessels in tempol-pretreated aged rats after 7 days is expressed as percent change from day 0 ( ${ }^{*} \mathrm{p}<0.05$ vs. same-animal control). The effect of tempol was completely inhibited by the eNOS inhibitor L-NAME ( $\mathrm{n}=$ 3-5 rats/group).

the ability of the NAD(P)H oxidase inhibitor and antioxidant apocynin [26] to promote collateral formation in aged Wistar rats. Apocynin was administered prior to model creation and continued until vessel diameters were obtained. Chronic apocynin treatment restored collateral growth (fig. $3 ; 18.3 \pm 2.2$ vs. $3.0 \pm 0.4 \%$, control) equivalent to that previously found with tempol. Similar increases in collateral growth capacity promoted by both tempol and apocynin confirm NAD $(\mathrm{P}) \mathrm{H}$ oxidase as a primary source of oxidant stress during vascular aging.

\section{Antioxidant Posttreatment}

To determine if antioxidant treatment could stimulate collateral growth if administered following, rather than prior to, an arterial ligation, the mesenteric collateral model was created in retired breeder WKY rats and the animals were allowed to recover for 7 days. Apocynin was then administered for an additional 7 days, and control and collateral artery diameters were determined. As shown in figure 4, apocynin posttreatment of the aged WKY significantly stimulated collateral growth (19.9 \pm 6.3 vs. $-0.02 \pm 2.3 \%$, same-animal control). Similar to Wistar rats (fig. 1), collaterals of aged WKY rats without treatment exhibited no significant enlarge- 


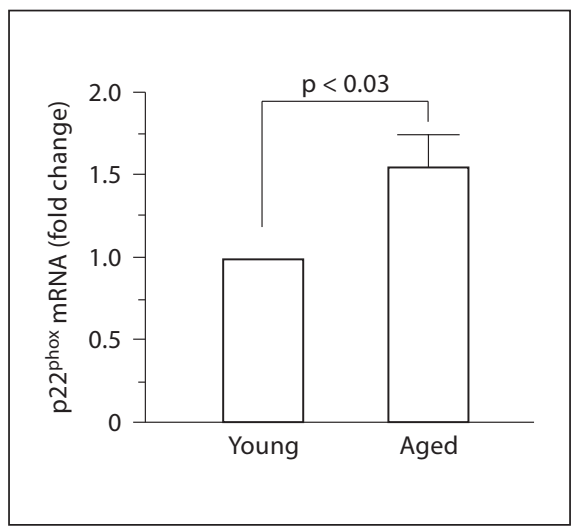

Fig. 2. Expression of $\mathrm{p} 22^{\text {phox }} \mathrm{mRNA}$ increases with aging. Increase in $\mathrm{p} 22^{\text {phox }}$ mRNA from aged mesenteric arteries is expressed as fold change compared to expression in individual young arteries after normalization to $\beta$-actin (analysis by oneway ANOVA; $\mathrm{n}=3$ ).

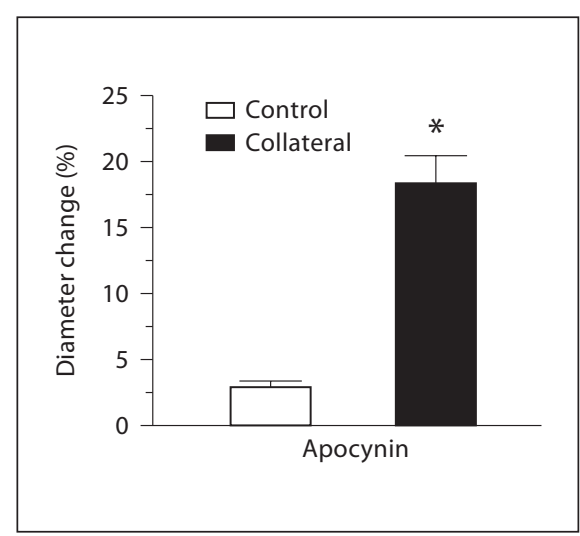

Fig. 3. Apocynin pretreatment reverses age-related collateral growth impairment. Diameter change of control and collateral vessels in apocynin-pretreated aged $\mathrm{Wi}$ star rats after 7 days is expressed as percent change from day $0\left({ }^{*} \mathrm{p}=0.03\right.$ vs. control, $\mathrm{n}=3)$.

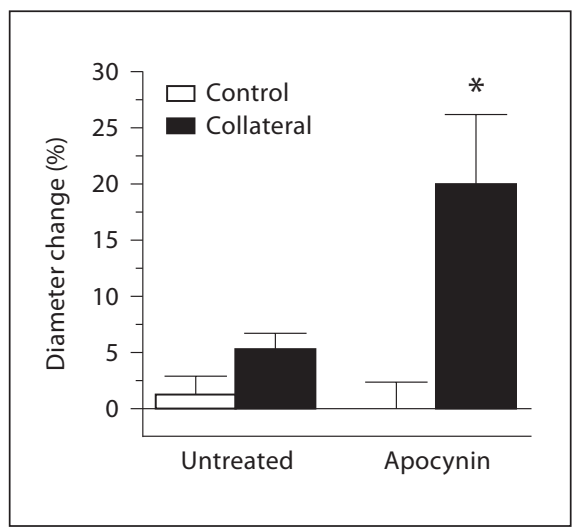

Fig. 4. Apocynin posttreatment promotes collateral growth in aged WKY rats. Apocynin treatment was initiated 7 days after model creation and maintained for 7 additional days. Diameter change of control and collateral vessels after 14 days is expressed as percent change from day $0\left({ }^{*} \mathrm{p}<0.05 \mathrm{vs}\right.$. same animal control, $\mathrm{n}=3$ /age). ment (fig. $4 ; 5.3 \pm 1.4$ vs. $1.3 \pm 1.6 \%$, same-animal control). The degree of collateral growth capacity for posttreated WKY is the same as that for aged Wistar rats pretreated with apocynin (fig. 3) and for pretreated aged WKY (data not shown).

\section{Discussion}

This study is the first to demonstrate that antioxidant treatment administered both before and substantially after arterial occlusion can significantly reverse collateral growth impairment during aging in rats. The results from initial experiments using tempol to decrease oxidative stress and promote collateral growth in aged rats, along with the observation of increased $\mathrm{p} 22^{\text {phox }}$ expression, suggest that excessive vascular superoxide is an important factor in the suppression of collateral growth during aging. This conclusion is consistent with other studies indicating that excessive concentrations of ROS result in impaired collateral development $[16,27,28]$. While some studies have questioned the role of $\mathrm{NO}$ in collateral growth [28$30]$, other studies [9, 31-34] have established an intact NO system to be required for shear-mediated outward remodeling, including collateral growth. The inhibition of the effect of tempol on collateral growth by L-NAME suggests that redox regulation of NO production is involved in the aging-related impairment in collateral growth.
The ability of tempol, a superoxide dismutase mimetic, to promote collateral growth may be related not only to a reduction in superoxide but also to increased hydrogen peroxide. Previous studies have shown that peroxide may act as a dilatory factor during vascular disease [35], and we have recently shown in SHR that peroxide mediates the flow-mediated production of NO [22]. Thus, peroxide could be one form of ROS involved in age-related effects on compensatory remodeling, and merits further investigation.

While increased expression of $\mathrm{p} 22^{\text {phox }} \mathrm{mRNA}$ in the retired breeder rat mesenteric arteries (fig. 2) does not itself indicate increased protein expression and $\mathrm{NAD}(\mathrm{P}) \mathrm{H}$ oxidase activation, it is consistent with many other studies that have shown $\mathrm{NAD}(\mathrm{P}) \mathrm{H}$ oxidase upregulation to be a primary source of vascular oxidant stress in cardiovascular disease [36-39] and during aging [7, 8,25 ]. Briones et al. [7] demonstrated increased p22 phox protein expression in mesenteric arteries of 22- to 24month-old Sprague-Dawley rats, and our results establish that upregulation of this $\mathrm{NAD}(\mathrm{P}) \mathrm{H}$ oxidase subunit has occurred at an earlier age in Wistar rats. The ability of chronically administered apocynin to stimulate collateral growth is consistent with an involvement for $\mathrm{NAD}(\mathrm{P}) \mathrm{H}$ oxidase in the aging-related impairment. The fact that collateral growth was stimulated to the same extent with either tempol (fig. 1), to remove oxygen radicals, or apocynin (fig. 3), to suppress oxygen radical 
formation, predicts that superoxide overproduction is an important suppressor of growth.

Recent results from Heumüller et al. [40] suggest that apocynin does not inhibit NAD(P)H oxidase in endothelial cells because myeloperoxidase (MPO) is not present, and thus dimers essential for activity cannot form. These results, however, are based on cultured HEK293 cells that were transfected to overexpress NAD $(\mathrm{P}) \mathrm{H}$ oxidase isoforms. Other studies have shown apocynin dimers to be present in endothelial cells [41] and MPO may be transferred into endothelial cells by a cytokeratin 1 pathway [42]. It is also likely that other peroxidases are present in endothelial cells in vivo that may substitute for MPO. Using in vitro vascular preparations, Schlüter et al. [43] have shown a requirement for exogenous peroxidase and hydrogen peroxide in order for apocynin to function as an $\mathrm{NAD}(\mathrm{P}) \mathrm{H}$ oxidase inhibitor. Recently, we have found that mesenteric arteries in the SHR [22] and retired breeder WKY [unpubl. observation] have in vivo hydrogen peroxide concentrations in excess of what was necessary for apocynin-mediated inhibition of superoxide production in the Schlüter study. In addition, we showed that apocynin reduced vascular peroxide concentrations to the same extent as the $\mathrm{NAD}(\mathrm{P}) \mathrm{H}$ oxidase peptide inhibitor gp91ds-tat [44]. Thus, although the possibility of nonspecific effects cannot be entirely excluded, it is likely that apocynin functioned as an $\mathrm{NAD}(\mathrm{P}) \mathrm{H}$ oxidase inhibitor in the aged mesenteric arteries.

While the results of this study do point to $\mathrm{NAD}(\mathrm{P}) \mathrm{H}$ oxidase as a major source of oxidant stress in aging vessels, with the caveats mentioned above, possible involvement of other ROS-generating pathways cannot be excluded. Tempol penetrates the mitochondrial membrane $[45,46]$, and other studies have implicated mitochondria [47] and xanthine oxidase [37, 48, 49] as vascular superoxide sources. However, it has been suggested that $\mathrm{NAD}(\mathrm{P}) \mathrm{H}$ oxidase influences xanthine oxidase as a master regulator [50] and can stimulate mitochondrial production of ROS [51]. Thus, such data are consistent with a role for $\mathrm{NAD}(\mathrm{P}) \mathrm{H}$ oxidase as the primary regulator of oxidant stress in the aged artery.

Previous results in our laboratory [16] showed that young WKY rats had the same mesenteric collateral growth capacity as young Wistar rats. However, it was not known if collateral growth in the WKY was impaired with aging. This must be established empirically, because mesenteric collateral growth is affected by aging to different extents depending on the rat genetic background [52]. We wanted to establish this impairment both to al- low comparison of aged data with previous results using the WKY, and also because the WKY is an inbred strain which is more genetically consistent, an important consideration for future molecular studies. Results from the retired breeder WKY experiments (fig. 4), previous studies [16], and preliminary data with apocynin pretreatment [unpubl. results] establish that this strain is analogous to the Wistar strain in terms of mesenteric collateral growth capacity.

In the majority of preclinical studies, pharmacological treatments are initiated at the time of or prior to model creation, which does not reflect the clinical reality of preexisting arterial insufficiency. The ability of apocynin to promote collateral growth when administration was begun 7 days following an arterial ligation (fig. 4) more closely models clinical situations of chronic arterial occlusion. The positive results suggest that antioxidant therapy could be clinically useful to stimulate collateral growth and improve tissue perfusion in patients with peripheral vascular disease. These results are particularly significant in light of the failure of growth factor therapy for peripheral arterial disease to improve patient outcome [53]. Although previous attempts to treat arterial insufficiency in humans with antioxidants have had highly variable outcomes, these results may be due to several factors, including subject age and a lack of prescreening for oxidant stress [54]. Recent results suggest that such prescreening can lead to significantly improved outcomes [55].

A limitation of this study was that only retired breeder and not older rats were used. This age range was chosen for study because the Wistar and WKY strains already have a complete impairment in collateral growth, and also because these strains are not readily available at older ages. It is possible that antioxidant treatment may not promote collateral growth in 18 - to 24 -month-old rats to the same extent as in retired breeders due to non-enzymatic protein crosslinking in the arterial wall [56]. Similar vascular wall structural alterations may be occurring at the age of the retired breeder rat, and if so, treatment with agents to break protein crosslinks, either alone or in combination with antioxidants, may be effective in reversing age-related impairments in collateral growth. A second limitation is that mean arterial pressures (MAP) were not measured, and it is possible that treatment-related alterations in MAP occurred which then influenced the arterial structure. We consider this possibility unlikely for three reasons: (1) the treatment duration was relatively short; (2) no diameter changes were detected in control arteries of treated rats, and (3) we have previous- 
ly shown in SHR that similar pharmacological treatments restore mesenteric collateral growth independent of alterations in MAP [16].

In conclusion, we have demonstrated that treatment with antioxidants can significantly reverse the impairment in collateral growth that occurs with aging. The results are consistent with the hypothesis that overproduction of ROS, perhaps due to $\mathrm{NAD}(\mathrm{P}) \mathrm{H}$ oxidase activation, is a major factor in suppressing compensatory vascular remodeling during aging. Additional studies are warranted to determine the redox mechanisms that regulate collateral growth due to the potential for the treatment of the rapidly increasing incidence of vascular occlusive disease in the aging population.

\section{Acknowledgments}

The authors would like to thank P. Melanie Pride, Kathryn E. Madren (supported by an American Physiological Society Frontiers in Physiology Professional Development Fellowship), and Randall G. Bills for their expert technical assistance with the animal surgeries, and H. Glenn Bohlen for his comments and suggestions. This work was supported in part by NIH grant HL 42898 and funds from the Department of Surgery (Indiana University).

\section{References}

$\checkmark 1$ Hirsch AT, Criqui MH, Treat-Jacobson D, Regensteiner JG, Creager MA, Olin JW, Krook SH, Hunninghake DB, Comerota AJ, Walsh ME, McDermott MM, Hiatt WR: Peripheral arterial disease detection, awareness, and treatment in primary care. JAMA 2001;286:1317-1324.

-2 Rosamond W, Flegal K, Friday G, Furie K, Go A, Greenlund K, Haase N, Ho M, Howard V, Kissela B, Kittner S, Lloyd-Jones D, McDermott M, Meigs J, Moy C, Nichol G, O’Donnell CJ, Roger V, Rumsfeld J, Sorlie P, Steinberger J, Thom T, Wasserthiel-Smoller S, Hong Y: Heart disease and stroke statistics - 2007 update: a report from the American Heart Association Statistics Committee and Stroke Statistics Subcommittee. Circulation 2007;115:e69-e171.

-3 Longland CJ: The collateral circulation of the limb; Arris and Gale lecture delivered at the Royal College of Surgeons of England on 4th February, 1953. Ann R Coll Surg Engl 1953;13:161-176

-4 Nakae I, Fujita M, Miwa K, Hasegawa K, Kihara Y, Nohara R, Miyamoto S, Ueda K, Tamaki S, Sasayama S: Age-dependent impairment of coronary collateral development in humans. Heart Vessels 2000;15:176-180.

5 Sun D, Huang A, Yan EH, Wu Z, Yan C, Kaminski PM, Oury TD, Wolin MS, Kaley G: Reduced release of nitric oxide to shear stress in mesenteric arteries of aged rats. Am J Physiol Heart Circ Physiol 2004;286:H2249H2256.

-6 Tuttle JL, Hahn TL, Sanders BM, Witzmann FA, Miller SJ, Dalsing MC, Unthank JL: Impaired collateral development in mature rats. Am J Physiol Heart Circ Physiol 2002; 283:H146-H155.

7 Briones AM, Montoya N, Giraldo J, Vila E: Ageing affects nitric oxide synthase, cyclooxygenase and oxidative stress enzymes expression differently in mesenteric resistance arteries. Auton Autacoid Pharmacol 2005; 15 Jablonski KL, Seals DR, Eskurza I, Monahan 25:155-162.

8 Hamilton CA, Brosnan MJ, McIntyre M, Graham D, Dominiczak AF: Superoxide excess in hypertension and aging: a common cause of endothelial dysfunction. Hypertension 2001;37:529-534.

9 Lloyd PG, Yang HT, Terjung RL: Arteriogenesis and angiogenesis in rat ischemic hindlimb: role of nitric oxide. Am J Physiol Heart Circ Physiol 2001;281:H2528-H2538.

10 Matsunaga T, Warltier DC, Weihrauch DW Moniz M, Tessmer J, Chilian WM: Ischemiainduced coronary collateral growth is dependent on vascular endothelial growth factor and nitric oxide. Circulation 2000;102: 3098-3103.

11 van der Loo B, Labugger R, Skepper JN, Bachschmid M, Kilo J, Powell JM, PalaciosCallender M, Erusalimsky JD, Quaschning T, Malinski T, Gygi D, Ullrich V, Luscher TF: Enhanced peroxynitrite formation is associated with vascular aging. J Exp Med 2000; 192:1731-1744.

$\checkmark 12$ Alp NJ, Channon KM: Regulation of endothelial nitric oxide synthase by tetrahydrobiopterin in vascular disease. Arterioscler Thromb Vasc Biol 2004;24:413-420.

13 Mukai Y, Shimokawa H, Higashi M, Morikawa K, Matoba T, Hiroki J, Kunihiro I, Talukder HMA, Takeshita A: Inhibition of renin-angiotensin system ameliorates endothelial dysfunction associated with aging in rats. Arterioscler Thromb Vasc Biol 2002;22: 1445-1450.

14 Cosentino F, Hurlimann D, Delli Gatti C, Chenevard R, Blau N, Alp NJ, Channon KM, Eto M, Lerch P, Enseleit F, Ruschitzka F, Volpe M, Luscher TF, Noll G: Chronic treatment with tetrahydrobiopterin reverses endothelial dysfunction and oxidative stress in hypercholesterolaemia. Heart 2008;94:487492.
KD, Donato AJ: High-dose ascorbic acid infusion abolishes chronic vasoconstriction and restores resting leg blood flow in healthy older men. J Appl Physiol 2007;103:17151721.

16 Miller SJ, Norton LE, Murphy MP, Dalsing MC, Unthank JL: The role of the renin-angiotensin system and oxidative stress in spontaneously hypertensive rat mesenteric collateral growth impairment. Am J Physiol Heart Circ Physiol 2007;292:H2523-2531.

17 Zalba G, Beaumont FJ, San Jose G, Fortuno A, Fortuno MA, Etayo JC, Diez J: Vascular $\mathrm{NADH} / \mathrm{NADPH}$ oxidase is involved in enhanced superoxide production in spontaneously hypertensive rats. Hypertension 2000; 35:1055-1061.

18 Unthank JL, Nixon JC, Burkhart HM, Fath SW, Dalsing MC: Early collateral and microvascular adaptations to intestinal artery occlusion in rat. Am J Physiol Heart Circ Physiol 1996;271:H914-H923.

19 Schnackenberg CG, Wilcox CS: Two-week administration of tempol attenuates both hypertension and renal excretion of 8-Iso prostaglandin f2alpha. Hypertension 1999; 33:424-428.

20 Welch WJ, Mendonca M, Blau J, Karber A, Dennehy K, Patel K, Lao YS, Jose PA, Wilcox CS: Antihypertensive response to prolonged tempol in the spontaneously hypertensive rat. Kidney Int 2005;68:179-187.

21 Yanes L, Romero D, Iliescu R, Cucchiarelli VE, Fortepiani LA, Santacruz F, Bell W, Zhang H, Reckelhoff JF: Systemic arterial pressure response to two weeks of tempol therapy in SHR: involvement of NO, the RAS, and oxidative stress. Am J Physiol Regul Integr Comp Physiol 2005;288:R903R908. 
22 Zhou X, Bohlen HG, Miller SJ, Unthank JL: $\mathrm{NAD}(\mathrm{P}) \mathrm{H}$ oxidase-derived peroxide mediates elevated basal and impaired flow-induced NO production in SHR mesenteric arteries in vivo. Am J Physiol Heart Circ Physiol 2008;295:H1008-H1016.

-23 Ellenby MI, Ernst CB, Carretero OA, Scicli AG: Role of nitric oxide in the effect of blood flow on neointima formation. J Vasc Surg 1996;23:314-322.

-24 Cai H, Griendling KK, Harrison DG: The vascular $\mathrm{NAD}(\mathrm{P}) \mathrm{H}$ oxidases as therapeutic targets in cardiovascular diseases. Trends Pharmacol Sci 2003;24:471-478.

-25 Mueller CF, Laude K, McNally JS, Harrison DG: ATVB in focus: redox mechanisms in blood vessels. Arterioscler Thromb Vasc Biol 2005;25:274-278

-26 Stolk J, Hiltermann TJ, Dijkman JH, Verhoeven AJ: Characteristics of the inhibition of NADPH oxidase activation in neutrophils by apocynin, a methoxy-substituted catechol. Am J Respir Cell Mol Biol 1994;11:95-102.

27 Reed R, Kolz C, Potter B, Rocic P: The mechanistic basis for the disparate effects of angiotensin II on coronary collateral growth. Arterioscler Thromb Vasc Biol 2008;28:6167.

28 Rocic P, Kolz C, Reed R, Potter B, Chilian WM: Optimal reactive oxygen species concentration and $\mathrm{p} 38 \mathrm{MAP}$ kinase are required for coronary collateral growth. Am J Physiol Heart Circ Physiol 2007;292:H2729-H2736.

29 Ceiler DL, De Mey JG: Chronic N(G)-nitroL-arginine methyl ester treatment does not prevent flow-induced remodeling in mesenteric feed arteries and arcading arterioles. Arterioscler Thromb Vasc Biol 2000;20: 2057-2063.

-30 Mees B, Wagner S, Ninci E, Tribulova S, Martin S, van Haperen R, Kostin S, Heil M, de Crom R, Schaper W: Endothelial nitric oxide synthase activity is essential for vasodilation during blood flow recovery but not for arteriogenesis. Arterioscler Thromb Vasc Biol 2007; 27:1926-1933.

- 31 Dumont O, Loufrani L, Henrion D: Key role of the NO-pathway and matrix metalloprotease-9 in high blood flow-induced remodeling of rat resistance arteries. Arterioscler Thromb Vasc Biol 2007;27:317-324.

- 32 Eitenmuller I, Volger O, Kluge A, Troidl K, Barancik M, Cai WJ, Heil M, Pipp F, Fischer S, Horrevoets AJ, Schmitz-Rixen T, Schaper W: The range of adaptation by collateral vessels after femoral artery occlusion. Circ Res 2006;99:656-662.

- 33 Tronc F, Wassef M, Esposito B, Henrion D, Glagov S, Tedgui A: Role of NO in flow-induced remodeling of the rabbit common carotid artery. Arterioscler Thromb Vasc Biol 1996;16:1256-1262.
$34 \mathrm{Yu}$ J, deMuinck ED, Zhuang Z, Drinane M, Kauser K, Rubanyi GM, Qian HS, Murata T, Escalante B, Sessa WC: Endothelial nitric oxide synthase is critical for ischemic remodeling, mural cell recruitment, and blood flow reserve. Proc Natl Acad Sci USA 2005; 102:10999-11004.

35 Phillips SA, Hatoum OA, Gutterman DD: The mechanism of flow-induced dilation in human adipose arterioles involves hydrogen peroxide during CAD. Am J Physiol Heart Circ Physiol 2007;292:H93-H100.

-36 Djordjevic T, BelAiba RS, Bonello S, Pfeilschifter J, Hess J, Gorlach A: Human urotensin II is a novel activator of NADPH oxidase in human pulmonary artery smooth muscle cells. Arterioscler Thromb Vasc Biol 2005;25:519-525.

37 Guzik TJ, Sadowski J, Guzik B, Jopek A, Kapelak B, Przybylowski P, Wierzbicki K, Korbut R, Harrison DG, Channon KM: Coronary artery superoxide production and nox isoform expression in human coronary artery disease. Arterioscler Thromb Vasc Biol 2006;26:333-339.

38 Loffredo L, Marcoccia A, Pignatelli P, Andreozzi P, Borgia MC, Cangemi R, Chiarotti F, Violi F: Oxidative-stress-mediated arterial dysfunction in patients with peripheral arterial disease. Eur Heart J 2007;28:608-612.

39 Vecchione C, Aretini A, Marino G, Bettarini U, Poulet R, Maffei A, Sbroggio M, Pastore L, Gentile MT, Notte A, Iorio L, Hirsch E, Tarone G, Lembo G: Selective Rac-1 inhibition protects from diabetes-induced vascular injury. Circ Res 2006;98:218-225.

40 Heumüller S, Wind S, Barbosa-Sicard E, Schmidt HH, Busse R, Schröder K, Brandes RP: Apocynin is not an inhibitor of vascular NADPH oxidases but an antioxidant. Hypertension 2008;51:211-217.

41 Johnson DK, Schillinger KJ, Kwait DM, Hughes CV, McNamara EJ, Ishmael F, O'Donnell RW, Chang MM, Hogg MG, Dordick JS, Santhanam L, Ziegler LM, Holland JA: Inhibition of NADPH oxidase activation in endothelial cells by ortho-methoxy-substituted catechols. Endothelium 2002;9:191-203.

42 Astern JM, Pendergraft WF 3rd, Falk RJ, Jennette JC, Schmaier AH, Mahdi F, Preston GA: Myeloperoxidase interacts with endothelial cell-surface cytokeratin 1 and modulates bradykinin production by the plasma kallikrein-kinin system. Am J Pathol 2007; 171:349-360.

-43 Schlüter T, Steinbach AC, Steffen A, Rettig R, Grisk O: Apocynin-induced vasodilation involves Rho kinase inhibition but not NADPH oxidase inhibition. Cardiovasc Res 2008;80: 271-279.

-44 Rey FE, Cifuentes ME, Kiarash A, Quinn MT, Pagano PJ: Novel competitive inhibitor of $\mathrm{NAD}(\mathrm{P}) \mathrm{H}$ oxidase assembly attenuates vascular $\mathrm{O}(2)(-)$ and systolic blood pressure in mice. Circ Res 2001;89:408-414.
45 Dessolin J, Schuler M, Quinart A, De Giorgi F, Ghosez L, Ichas F: Selective targeting of synthetic antioxidants to mitochondria: towards a mitochondrial medicine for neurodegenerative diseases? Eur J Pharmacol 2002;447:155-161.

-46 Ueda A, Nagase S, Yokoyama H, Tada M, Noda H, Ohya H, Kamada H, Hirayama A, Koyama A: Importance of renal mitochondria in the reduction of TEMPOL, a nitroxide radical. Mol Cell Biochem 2003;244:119124.

47 Griendling KK, FitzGerald GA: Oxidative stress and cardiovascular injury. Part I: basic mechanisms and in vivo monitoring of ROS. Circulation 2003;108:1912-1916.

-48 Landmesser U, Harrison DG, Drexler H: Oxidant stress - a major cause of reduced endothelial nitric oxide availability in cardiovascular disease. Eur J Clin Pharmacol 2006; 62:13-19.

49 Newaz MA, Yousefipour Z, Oyekan A: Oxidative stress-associated vascular aging is xanthine oxidase-dependent but not $\mathrm{NAD}(\mathrm{P}) \mathrm{H}$ oxidase-dependent. J Cardiovasc Pharmacol 2006;48:88-94.

50 McNally JS, Davis ME, Giddens DP, Saha A, Hwang J, Dikalov S, Jo H, Harrison DG: Role of xanthine oxidoreductase and $\mathrm{NAD}(\mathrm{P}) \mathrm{H}$ oxidase in endothelial superoxide production in response to oscillatory shear stress. Am J Physiol Heart Circ Physiol 2003;285: H2290-H2297.

51 Doughan AK, Harrison DG, Dikalov SI: Molecular mechanisms of angiotensin II-mediated mitochondrial dysfunction: linking mitochondrial oxidative damage and vascular endothelial dysfunction. Circ Res 2008; 102: 488-496.

-52 Sheridan KM, Ferguson MJ, Distasi MR, Witzmann FA, Dalsing MC, Miller SJ, Unthank JL: Impact of genetic background and aging on mesenteric collateral growth capacity in Fischer 344, Brown Norway, and Fischer 344 x Brown Norway hybrid rats. Am J Physiol Heart Circ Physiol 2007;293:H3498H3505

53 Simons M: Angiogenesis: where do we stand now? Circulation 2005;111:1556-1566.

54 Griendling KK, FitzGerald GA: Oxidative stress and cardiovascular injury. Part II: animal and human studies. Circulation 2003; 108:2034-2040.

55 Milman U, Blum S, Shapira C, Aronson D, Miller-Lotan R, Anbinder Y, Alshiek J, Bennett L, Kostenko M, Landau M, Keidar S, Levy Y, Khemlin A, Radan A, Levy AP: Vitamin $\mathrm{E}$ supplementation reduces cardiovascular events in a subgroup of middle-aged individuals with both type 2 diabetes mellitus and the haptoglobin 2-2 genotype: a prospective double-blinded clinical trial. Arterioscler Thromb Vasc Biol 2008;28:341-347.

56 Vasan S, Foiles P, Founds H: Therapeutic potential of breakers of advanced glycation end product-protein crosslinks. Arch Biochem Biophys 2003;419:89-96. 